\title{
Research Paper: Subjective Wellbeing and Interpersonal Problems in the Mothers of Students With Learning Disabilities
}

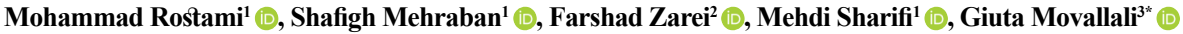 \\ 1. Department of Counseling, University of Social Welfare and Rehabilitation Sciences, Tehran, Iran. \\ 2. Department of Counseling, Faculty of Psychology and Education, Kharazmi University, Tehran, Iran. \\ 3. Pediatric Neurorehabilitation Research Center, University of Welfare and Rehabilitation Sciences, Tehran, Iran.
}

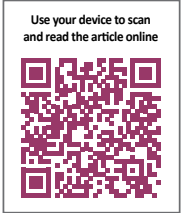

ditation: Rostami M, Mehraban S, Zarei F, Sharifi M, Movallai G. Subjective Wellbeing and Interpersonal Problems in the Mothers of Students With Learning Disabilities. Iranian Rehabilitation Journal. 2019; 17(3):207-214. http://dx.doi.org/10.32598/ irj.17.3.207

dof http://dx.doi.org/10.32598/irj.17.3.207

Article info:

Received: 10 Feb 2019

Accepted: 28 May 2019

Available Online: 01 Sep 2019

\section{Keywords:}

Dialectical behavior therapy,

Subjective wellbeing,

Interpersonal problems

\section{ABSTRACT}

Objectives: The challenges of caring for students with learning disabilities expose their mothers to mental health problems; however, less attention has been paid to treatment interventions for them. The present study aimed to examine the effectiveness of Dialectical Behavior Therapy (DBT) group training on subjective wellbeing and interpersonal relationships in the mothers of students with learning disabilities.

Methods: In this experimental research, 40 mothers of students with learning disabilities were selected through simple random sampling method. They were randomly divided into two experimental and control groups after observing ethical issues. The study participants completed the subjective wellbeing and interpersonal problems questionnaires Then, the multivariate analysis of covariance was used to analyze the obtained data.

Results: There were significant differences between the two groups $\left(\mathrm{F}_{30.9}=\mathrm{P}<0.001\right)$ in subjective wellbeing and interpersonal relationships in the mothers of students with learning disabilities.

Discussion: DBT skills training can be useful both alone and in combination with other training methods for reducing interpersonal problems and improving subjective wellbeing in the mothers of students with learning disabilities.

\section{* Corresponding Author:}

Guita Movallali, PhD.

Address: Pediatric Neurorehabilitation Research Center, University of Welfare and Rehabilitation Sciences, Tehran, Iran.

Tel: +98 (21) 22180083-92

E-mail:drgmovallali@gmail.com 


\section{Highlights}

- The problems of caring for children with learning disabilities expose parents to mental health problems.

- Dialectical behavior therapy skills training as a type of psychotherapy can help reduce the psychological problems and improve subjective wellbeing in the mothers of students with learning disabilities.

\section{Plain Language Summary}

Compared to healthy children's parents, the parents of students with learning disabilities suffer from decreased men$\mathrm{tal} /$ general health and increased anxiety, depression, and aggression. The main motive for conducting the present study was the considerable psychological challenges faced by these parents and the lack of studies related to mental rehabilitation interventions for them. The obtained results indicated that dialectical behavior therapy skills training could effectively improve mental health status in these mothers.

\section{Introduction}

he Diagnostic and Statistical Manual of $\Gamma$ Mental Disorders, $5^{\text {th }}$ Edition (DSM-5) classifies learning disorders under neuropsychological disorders. This category includes all different disorders with early childhood and preschool onset, such as learning disorders and relational disorders. Learning disabilities include disorders that are characterized by problems in academic achievement or routine function [1]. The parents of exceptional children face greater socioeconomic and emotional problems with a destructive nature [2]. In such situations, all family members are hurt, and their functions are disturbed; however, mothers face more psychological problems. This is due to their stronger traditional care responsibility for their children [3]. The problems of caring for these children expose the parents to mental health problems [4].

Subjective wellbeing and its components (psychosocial and emotional wellbeing) are among the most important factors that the mothers of students with learning disabilities struggle with [5]. Subjective wellbeing refers to the individuals' perceptions of their life quality (psychosocial and emotional aspects) [6]. Interpersonal problems include individuals' problems in assertiveness, connection with people, accommodation, intimacy, responsibility, and control. These issues prevent the development of healthy relationships, collaboration with others, and appreciation; they also lead to irrational social responses [7]. Compared to the parents of healthy children, the parents of students with learning disabilities suffer from decreased mental/ general health and increased anxiety, depression, and aggression [4].
In general, Cognitive Behavioral Therapy (CBT) seems to be effective in improving subjective wellbeing as well as interpersonal problems in the mothers of students with learning disabilities. However, Dialectical Behavior Therapy (DBT), a type of CBT, can be most effective in this regard. This is due to its several unique features, as follows: 1. DBT combines the acceptance and empathy of client-centered approaches with the problem-solving skills of CBT and social skills training [8]; 2. DBT is a well-structured therapeutic program with feasible applicability for therapists [9]; and 3. DBT has systematic strategies for the assessment and treatment of several other problems [8].

Few studies have directly investigated the effectiveness of DBT on subjective wellbeing and interpersonal relationships in the mothers of students with learning disabilities. Some similar research studies have reported the effectiveness of this method. A study suggested that DBT effectively improves interpersonal relationships and emotion regulation in these students [10]. Other studies also documented that individuals who had received DBT, enjoyed a higher quality of life, emotional control, and mental health, compared to their peers [11].

Overall, research suggests that DBT improves impulsivity, self-harm, emotion regulation, and several mood and emotional problems, such as depression; anxiety; anger; emotional instability; and irritability $[8,12]$. Children with learning disability influence their parents' subjective wellbeing [13], and interpersonal and emotional relationships [14]. Moreover, significant changes occur in the rehabilitation of families with students with learning disabilities. This therapeutic model has not been applied to the mothers of students with learning disabilities. Thus, conducting such studies, as a basis for further 
investigations and the development of appropriate interventions for improving subjective wellbeing and interpersonal relationships in this group is essential.

Additionally, the strong evidence for the effectiveness of DBT suggests further research in this area. Furthermore, parental benefits from the consequences of more effective psychotherapy interventions call for this study. Therefore, the present study intended to examine the effectiveness of DBT group training on the improvement of subjective wellbeing and the reduction of interpersonal problems in the mothers of students with learning disabilities.

\section{Methods}

This was an experimental research with pre-test-posttest and a control group design. The statistical population included all mothers of middle school students with learning disabilities in Tehran City, Iran (2016-2017). In this research, a simple cluster sampling method was used. In the first step, the district 5 of the municipality was randomly selected. Then, 14 middle schools and finally, 7 schools were randomly selected. Accordingly, teachers were interviewed, and according to the DSM5 criteria, the suspected students of learning disabilities were identified ( $\mathrm{n}=150$ students). The interviews were conducted by three experienced postgraduate clinical psychologists.

After observing the ethical issues, the mothers of students with learning disabilities were invited, and the research objectives were explained to them. Then, Subjective Wellbeing Scale (SWS) and Inventory of Interpersonal Problems (IIP) were administered on them. According to the inclusion criteria (obtaining 1.5 standard deviations higher than mean score in IIP and 1.5 standard deviations lower than mean score in SWS), 40 mothers were randomly selected and allocated into experimental and control groups (20 subjects in each group). To employ the experimental method, each subgroup must have at least 15 members [15]. To increase the external credibility and to observe the representativeness of samples to the population, 20 subjects were considered in each group. The present study was reviewed and approved by the Ethics Committee of the University of Social Welfare and Rehabilitation Sciences, Tehran, Iran.

The inclusion criteria were a diagnosis of learning disabilities, 12-16 years of age, obtaining an average Intelligence Quotient (IQ) score in Raven's Progressive Matrices test, and the lack of sensory and neurological disabilities. The exclusion criteria included severe simultaneous disorders, such as ADHD and depression, and obtaining an IQ score below 85 in Raven's Progressive Matrices test. These criteria were approved by student's academic records, teacher reports, and structured clinical interviews based on DSM-5.

\section{Study instruments}

Keyes and Magyar-Moe's Subjective Wellbeing Scale: The questionnaire was designed by Keyes and MagyarMoe [16]. It includes three emotional, psychological, and social subscales. The questionnaire was performed and validated on 57 subjects by Golestani-Bakht [17]. Using Cronbach's $\alpha$, its internal consistency coefficient has been calculated as $(0.80)$ for the total questionnaire, and (0.86), (0.80), and (0.61), for emotional, psychological, and social wellbeing subscales, respectively [17]. The correlation of SWB questionnaire with Subjective Happiness Scale (SHS) of Lyubomirsky and Lepper [18] was equal to $(0.78)$. The same value for its subscales were $(0.76),(0.64)$, and $(0.76)$ for emotional, psychological, and social wellbeing, respectively. The internal consistency coefficients calculated in the present study were $(0.79),(0.76)$, and (0.62), for emotional, psychological, and social wellbeing, respectively.

Emotional Wellbeing Subscale Using 12 items, assesses individuals' positive and negative emotions occurring in the recent month. Respondents rate their general feelings on a 5-point Likert-type scale from 1 (all the times) to 5 (never). Scores 1 and 5 reflect the worst and best emotional states, respectively.

Social Wellbeing Subscale includes 15 items and 5 components (popularity and social acceptance, social realistic, community involvement, social connection, social solidarity). Respondents rate their general assessment on a 7-degree Likert-type scale from 1 (strongly disagree) to 7 (strongly agree).

Psychological Wellbeing Subscale includes 18 items and 6 components (self-acceptance, personal growth, and purpose in life, environmental mastery, autonomy, and positive relations with others). Respondents rate their general psychological assessment on a 7-point Likert-type scale from 1 (strongly disagree) to 5 (strongly agree). Higher scores indicate better psychological wellbeing. The obtainable scores range from 1 to 126 .

Inventory of Interpersonal Problems (IIP-32) is a selfreport instrument; its items probe the problems individuals regularly experience in interpersonal relationships. This version has been developed by Barkham, Hardy, and Startup [19], as a short form of the main version 
Table 1. The contents of DBT group training

\begin{tabular}{|c|c|}
\hline DBT Training Session & Contents \\
\hline 1 & $\begin{array}{l}\text { Preliminary explanations, conceptualizing the problem, preparing the subjects and administrating pre- } \\
\text { test, preparing a list of enjoyable activities, and including them in the weekly program }\end{array}$ \\
\hline $2 \& 3$ & Mindfulness training (emotional consciousness and wise consciousness) \\
\hline 4 & $\begin{array}{l}\text { Examining the thoughts and feelings and identifying internal and external coping responses; home- } \\
\text { work assignment }\end{array}$ \\
\hline 5 & $\begin{array}{c}\text { Distress tolerance training (stability in crises, distracting, relaxation training, calming oneself down } \\
\text { through } 6 \text { senses and mindfulness training) }\end{array}$ \\
\hline 6 & $\begin{array}{c}\text { Helping mothers to practice controlling aggressive behaviors, self-blame, and blaming others and were } \\
\text { provided with feedback to achieve a reasonable level of mastery and control }\end{array}$ \\
\hline 7 & $\begin{array}{c}\text { Acceptance without judgment and prejudice, and reducing the physical harm of overeating, anorexia, } \\
\text { narcotics use, alcohol consumption, discussing exercise, ailment, sleep health, stress; identifying self- } \\
\text { harm behaviors, self-monitoring without judgment, reducing the cognitive vulnerability, and increasing } \\
\text { positive emotions }\end{array}$ \\
\hline $8 \& 9$ & $\begin{array}{l}\text { Emotion regulation training (the aims of training, knowledge about the importance of emotions, the } \\
\text { identification of emotions, reducing emotional suffering, increasing positive emotion, and problem- } \\
\text { solving skills) }\end{array}$ \\
\hline $10 \& 11$ & $\begin{array}{l}\text { Improving interpersonal efficacy (maintaining healthy relationships with children, family, and relations, } \\
\text { interest, etc.) }\end{array}$ \\
\hline 12 & Wrap-up, practicing and reviewing the sessions, and post-test administration \\
\hline
\end{tabular}

Iranian Rehabilitation Journal

(127-item form) for clinical use. Considering four items having the highest factor loading in each subscale, this form was derived from 127-item form based on exploratory factor analysis [20].

This scale includes 6 subscales, as follows: assertiveness and connection with people, openness, considering others, aggression, supporting others, and collaboration with others, $(0.63)$ for dependency to others, these items are rated on a 5-point Likert-type scale from 0 (by no means) to 5 (extremely). Its internal consistency coefficients were calculated as 0.83 for assertiveness and connection with people, 0.63 for openness, $(0.60)$ for considering others, $(0.83)$ for aggression, $(0.71)$ for supporting others and collaboration with others, $(0.63)$ for dependency to others, and (0.82) for the total scale. This indicates the desirability of scale reliability [21]. In the present study, the internal consistency coefficient was calculated as 0.79 for the total scale, and $(0.81),(0.70)$, (0.64), (0.79), (0.68), and (0.68) for assertiveness and connection with people, openness, considering others, aggression, supporting others and collaboration with others, and dependency to others, respectively.

DBT Skills Training Program: DBT is mainly psychoeducational-based and emphasizes on behavioral skills (Table 1). It has been planned based on Linehan [9] stud- ies on treating Borderline Personality Disorder (BPD) in 3 months (12 sessions of 60 minutes). This treatment program was initially used to treat other mental conditions. The mothers received DBT training once a week at a place designated by the Education Organization according to the following contents. The training was provided by one trained rehabilitation counselor with a $\mathrm{PhD}$ degree.

After obtaining permission from Tehran Education Organization, observing the ethical considerations, and expressing the research goals, informed consent was obtained from the mothers. Then, the subjects completed the IIP and SWS. Accordingly, the mothers of students with learning disabilities were randomly assigned to the experimental and control groups. We briefed the study participants and stated the study objectives to them. Moreover, the subjects were invited to attend the training course. Before the training sessions, a pre-test was performed in both groups, and they were requested to complete the questionnaires carefully.

Then, the experimental group received dialectic behavior therapy training. The intervention included 12 group sessions of one-hour that were held once a week. Two weeks after the completion of training, both groups completed the post-test. Then, the collected data 
were analyzed by Multivariate Analysis of Covariance (MANCOVA) in SPSS.

The study subjects were informed about their right to discontinue the research as desired. Meanwhile, ensuring the confidentiality of information and preparing mothers mentally and spiritually to participate in the research were the ethical considerations of this study.

\section{Results}

Before data analysis, the data were examined in terms of the assumptions of covariance analysis. In this respect, 5 assumptions of covariance analysis of the normality of variances, linearity, the multicollinearity, homogeneity of variance, and the homogeneity of regression were examined. (Table 2). indicates the Mean $\pm \mathrm{SD}$ scores of subjective wellbeing and interpersonal problems.

To observe the assumptions of MANCOVA (as a parametric test), Box's test and Levene's test were used in advance. Box's test result was not significant for any of the variables $(\mathrm{P}=0.224, \mathrm{~F}=1.146, \mathrm{BOX}=69.38)$. Therefore, the condition of homogeneity of variance/ covariance matrices has been met. The Levene's test result was not significant for any of the variables. Therefore, the condition of equality of intergroup variances has also been met.
According to Table 3, after controlling pre-test scores, DBT has a significant effect on the components of subjective wellbeing and interpersonal problems in post-test stage $\left(\mathrm{P}<0.001, \mathrm{~F}_{30,9}=72.91\right)$.

According to MANOVA results, after controlling the pre-test scores, DBT has a significant effect on subjective wellbeing $(\mathrm{P}<0.001, \mathrm{~F} 38,1=31.38)$ and interpersonal problems $(\mathrm{P}<0.001, \mathrm{~F} 38,1=301.27)$. These findings suggest an increase of subjective wellbeing and decrease of interpersonal problems in the experimental group members, compared to the controls (Table 4).

\section{Discussion}

The present study examined the effectiveness of DBT group training on subjective wellbeing and interpersonal problems in the mothers of students with learning disabilities. Findings revealed that DBT group training affects subjective wellbeing in these mothers. These findings are consistent with other studies suggesting that DBT is effective in reducing impulsive behaviors, such as emotional disorders, anger, and instability [8, 10-12, 22]. The relationships between mothers and children deeply affect children's biopsychosocial and economic health [23].

Table 2. Comparing the Mean \pm SD scores of IIP and SWS (pre-test and post-test)

\begin{tabular}{|c|c|c|c|c|c|}
\hline \multirow{3}{*}{ Variable } & \multirow{3}{*}{ Component } & \multicolumn{4}{|c|}{ Mean $\pm S D$} \\
\hline & & \multicolumn{2}{|c|}{ Experimental Group } & \multicolumn{2}{|c|}{ Control Group } \\
\hline & & Pre-Test & Post-Test & Pre-Test & Post-Test \\
\hline \multirow{4}{*}{$\begin{array}{l}\text { Subjective } \\
\text { wellbeing }\end{array}$} & Social wellbeing & $48.9 \pm 1.44$ & $57 \pm 1.41$ & $47.4 \pm 1.46$ & $49.8 \pm 3$ \\
\hline & Emotional wellbeing & $38.5 \pm 2$ & $46 \pm 1.56$ & $37.5 \pm 1.82$ & $39.7 \pm 2$ \\
\hline & Psychological wellbeing & $69.35 \pm 1.75$ & $77.1 \pm 2$ & $68.80 \pm 1.1$ & $69.1 \pm 1.25$ \\
\hline & Total & $156.68 \pm 3$ & $180.1 \pm 3.5$ & $153.7 \pm 2.7$ & $158.7 \pm 1.56$ \\
\hline \multirow{7}{*}{$\begin{array}{l}\text { Interpersonal } \\
\text { problems }\end{array}$} & Assertiveness & $17.4 \pm 1.18$ & $11.4 \pm 1.9$ & $16.9 \pm 1.3$ & $15.8 \pm 1.5$ \\
\hline & Openness & $11.5 \pm 1.31$ & $6.8 \pm 1.3$ & $11.6 \pm 0.94$ & $11.7 \pm 1.2$ \\
\hline & Considering others & $12.5 \pm 1.19$ & $6.1 \pm 1.4$ & $12 \pm 1.2$ & $11.2 \pm 2.3$ \\
\hline & Aggression & $11.8 \pm 1.6$ & $5.7 \pm 1$ & $11 \pm 1.4$ & $10.8 \pm 1.4$ \\
\hline & $\begin{array}{l}\text { Supporting others and } \\
\text { collaboration with others }\end{array}$ & $18.7 \pm 1.4$ & $11.7 \pm 1.1$ & $18 \pm 2.1$ & $17.8 \pm 2.4$ \\
\hline & Dependency to others & $8.3 \pm 0.93$ & $4.4 \pm 1.3$ & $8.9 \pm 1.1$ & $7.9 \pm 0.91$ \\
\hline & Total & $80.30 \pm 3$ & $46.2 \pm 4$ & $78.5 \pm 3$ & $75.3 \pm 6.3$ \\
\hline
\end{tabular}

Iranian Rehabilitation Journal 
Table 3. MANCOVA results on the mean post-test scores of variables

\begin{tabular}{cccccccc}
\hline Test & Value & Hypothesis df & Error df & F & P & Eta & Sig. \\
\hline Pillai's Trace & 0.584 & 9 & 30 & 72.91 & $\leq 0.001$ & 0.584 & 0.01 \\
Wilks' Lambda & 0.342 & 9 & 30 & 72.91 & $\leq 0.001$ & 0.584 & 0.01 \\
Hotelling's Trace & 16.485 & 9 & 30 & 72.91 & $\leq 0.001$ & 0.584 & 0.01 \\
\hline Roy's Largest Root & 16.485 & 9 & 30 & 72.91 & $\leq 0.001$ & 0.584 & 0.01 \\
\hline
\end{tabular}

Iranian Rehabilitation Journal

In other words, weak familial interactions, including unstable and punishment-based parenting, cold and dismissive parenting, unstable and strict disciplinary rules, insecure attachment, insufficient parental control, spending limited time with child, and the lack of positive relationship and empathy [3] are regarded as risk factors; they expose these children to the risk of aggressive behaviors [24]. DBT is a well-structured therapy that uses behavioral and dialectical techniques (self-monitoring, meditation, encounter, and behavior contract). Therefore, the obtained changes remain consistent over time [25].

Combining mindfulness practices, emotion regulation, and behavioral practices, DBT teaches mothers to observe the biopsychological and behavioral outcomes non-judgmentally [9]. In addition, it encourages accepting these behaviors unconditionally; so that this acceptance leads to positive emotions.
Additionally, by practicing these components, mothers can acquire problem-solving and coping skills in daily life in the face of emotional struggles. This may be a combination of behavior therapy and cognitive problem-solving [9]. Overall, risky behaviors decrease, and the ability to solve the interpersonal relationship conflicts improves in the mothers of children with learning disabilities. While interacting with others, their self-confidence increases and undesirable daily experiences decrease. Moreover, affective instability and ability to regulate negative emotions and tensions improve subjective wellbeing and interpersonal relationships in this group.

The findings suggested that DBT group training effectively decrease the interpersonal problems in the mothers of students with learning disabilities. These findings are consistent with other studies $[8,11,12]$. The necessary elements of this therapy include interpersonal efficacy,

Table 4. MANCOVA results for variables in the experimental and control groups

\begin{tabular}{|c|c|c|c|c|c|c|c|c|c|c|}
\hline \multirow[b]{2}{*}{ Variable } & \multirow[b]{2}{*}{ Component } & \multirow[b]{2}{*}{ SS } & \multicolumn{3}{|c|}{ df } & \multirow[b]{2}{*}{ TOMS } & \multirow[b]{2}{*}{$\mathbf{F}$} & \multirow[b]{2}{*}{$\mathbf{P}$} & \multirow[b]{2}{*}{ Eta } & \multirow[b]{2}{*}{ Sig. } \\
\hline & & & G & $\mathbf{E}$ & $\mathbf{T}$ & & & & & \\
\hline \multirow{4}{*}{$\begin{array}{l}\text { Subjective } \\
\text { wellbeing }\end{array}$} & Social wellbeing & 511.22 & 1 & 38 & 40 & 511.22 & 92.26 & $\leq 0.001$ & 0.70 & 0.01 \\
\hline & Emotional wellbeing & 390.36 & 1 & 38 & 40 & 390.36 & 106.21 & $\leq 0.001$ & 0.73 & 0.01 \\
\hline & $\begin{array}{l}\text { Psychological } \\
\text { wellbeing }\end{array}$ & 640 & 1 & 38 & 40 & 640 & 226.02 & $\leq 0.001$ & 0.74 & 0.01 \\
\hline & Total & 4579.60 & 1 & 38 & 40 & 4579.60 & 31.383 & $\leq 0.001$ & 0.70 & 0.01 \\
\hline \multirow{7}{*}{$\begin{array}{l}\text { Interpersonal } \\
\text { problems }\end{array}$} & Assertiveness & 198.02 & 1 & 38 & 40 & 198.02 & 64.12 & $\leq 0.001$ & 0.62 & 0.01 \\
\hline & Openness & 240.10 & 1 & 38 & 40 & 240.10 & 143.90 & $\leq 0.001$ & 0.71 & 0.01 \\
\hline & Considering others & 255.02 & 1 & 38 & 40 & 255.02 & 68.36 & $\leq 0.001$ & 0.64 & 0.01 \\
\hline & Aggression & 265.22 & 1 & 38 & 40 & 265.22 & 155.65 & $\leq 0.001$ & 0.80 & 0.01 \\
\hline & $\begin{array}{l}\text { Supporting others } \\
\text { and collaboration } \\
\text { with others }\end{array}$ & 372.10 & 1 & 38 & 40 & 372.10 & 97.98 & $\leq 0.001$ & 0.72 & 0.01 \\
\hline & $\begin{array}{l}\text { Dependency } \\
\text { to others }\end{array}$ & 122.50 & 1 & 38 & 40 & 122.50 & 95.78 & $\leq 0.001$ & 0.71 & 0.01 \\
\hline & Total & 8497.22 & 1 & 38 & 40 & 8497.22 & 301.27 & $\leq 0.001$ & 0.73 & 0.01 \\
\hline
\end{tabular}


appropriate emotional responding to the feelings of others, and the fundamental process of real psychological changes. Combining its four main skills with client-centered therapy, this approach paves the way for improvement in social relationships, links the individuals with the social environment, and prevents harming others [9]. These changes contribute to improving the quality of interpersonal relationships.

Furthermore, in interpersonal skills training (using DBT components), the mothers of these children become aware of negative thoughts and emotions, causing problems in developing a relationship with others. They learn to ignore maladaptive self-talks and labeling. They also replace conflicting interpretations with optimistic ones in harmful situations. In DBT, the client is encouraged to challenge his/ her disturbing thoughts and eliminate the alternative self-talks that cause biopsychological disorders [7].

In addition, group-based therapies have many benefits. Group therapy provides an opportunity for mothers to meet and discuss similar problems. Eliminating the feelings of being special and alone are among the major consequences of group therapy; it not only facilitates the members' internal comfort but also helps develop their relationships outside the therapeutic environment. They could also support each other within the treatment environment [25].

The present findings may be applied in different domains, including psychology, counseling, and education. Efficacy of DBT training lies in the combination of psychoeducational and supportive methods. Limiting the study population to Tehran City and the lack of a standard training place were some limitations to this research. Therefore, future research is recommended to consider these weak points to help the generalization of findings. It is also recommended to apply this method for other disorders, such as pain disorders, migraine, trichotillomania, oppositional defiant disorder, post-traumatic stress disorder, physically and emotionally abused women and children, and schizophrenia.

\section{Conclusion}

DBT skills training can be useful both alone and in combination with other training methods to reduce interpersonal problems and improve subjective wellbeing in the mothers of students with learning disabilities.

\section{Ethical Considerations}

\section{Compliance with ethical guidelines}

The present study was reviewed and approved by the Ethical Committee of the University of Social Welfare and Rehabilitation Sciences, Tehran, Iran.

\section{Funding}

This article has been extracted from a research project sponsored by the Pediatric Neurorehabilitation Research Center, University of Social Welfare and Rehabilitation Sciences.

\section{Authors' contributions}

Methodology: Mohammad Rostami, Shafigh Mehraban; Investigation: Guita Movallai; Writing-original draft: Mohammad Rostami, Farshad Zarei, Shafigh Mehraban, Mehdi Sharifi; Writing-review \& editing: Guita Movallai, Mehdi Sharifi; Funding acquisition: Mohammad Rostami, Guita Movallai; Resources: Farshad Zarei, Mohammad Rostami, Shafigh Mehraban; Supervision: Guita Movallai.

\section{Conflict of interest}

The authors declared no conflict of interest.

\section{References}

[1] Snowling MJ, Hulme C. Annual research review: The nature and classification of reading disorders: A commentary on proposals for DSM-5. Journal of Child Psychology and Psychiatry. 2012; 53(5):593-607. [DOI:10.1111/j.1469-7610.2011.02495.x] [PMID] [PMCID]

[2] Matin A, Looyeh MY, Afrooz GA, Dezhkam M. The effect of group rational emotive behavior restructuring on mental health of parents of exceptional children. Procedia-Social and Behavioral Sciences. 2012; 46:1872-5. [DOI:10.1016/j.sbspro.2012.05.394]

[3] Jenaabadi H. The study and comparison of stress levels and coping strategies in parents of exceptional (mentally retarded, blind and deaf) and normal children in Zahedan. Procedia-Social and Behavioral Sciences. 2014; 114:197-202. [DOI:10.1016/j.sbspro.2013.12.684]

[4] Gallagher S, Hannigan A. Depression and chronic health conditions in parents of children with and without developmental disabilities: The growing up in Ireland cohort study. Research in Developmental Disabilities. 2014; 35(2):448-54. [DOI:10.1016/j.ridd.2013.11.029] [PMID] 
[5] Lee J. Maternal stress, well-being, and impaired sleep in mothers of children with developmental disabilities: A literature review. Research in Developmental Disabilities. 2013; 34(11):4255-73. [DOI:10.1016/j.ridd.2013.09.008] [PMID]

[6] Kaya H, Bodur G, Yalnı N. The relationship between high school students' attitudes toward future and subjective well-being. Procedia-Social and Behavioral Sciences. 2014; 116:3869-73. [DOI:10.1016/j.sbspro.2014.01.857]

[7] Gerhart JI, Baker CN, Hoerger M, Ronan GF. Experiential avoidance and interpersonal problems: A moderated mediation model. Journal of Contextual Behavioral Science. 2014; 3(4):291-8. [DOI:10.1016/j.jcbs.2014.08.003]

[8] Frazier SN, Vela J. Dialectical behavior therapy for the treatment of anger and aggressive behavior: A review. Aggression and Violent Behavior. 2014; 19(2):156-63. [DOI:10.1016/j. avb.2014.02.001]

[9] Linehan MM, Cochran BN, Kehrer CA. Dialectical behavior therapy for borderline personality disorder. In: Barlow $\mathrm{DH}_{\text {, }}$ editor. Clinical Handbook of Psychological Disorders: A StepBy-Step Treatment Manual. New York: Guilford Press; 2001.

[10] Koons CR, Chapman AL, Betts BB, Morse N, Robins CJ. Dialectical behavior therapy adapted for the vocational rehabilitation of significantly disabled mentally ill adults. Cognitive and Behavioral Practice. 2006; 13(2):146-56. [DOI:10.1016/j. cbpra.2005.04.003]

[11] Pasieczny N, Connor J. The effectiveness of dialectical behaviour therapy in routine public mental health settings: An Australian controlled trial. Behaviour Research and Therapy. 2011; 49(1):4-10. [DOI:10.1016/j.brat.2010.09.006] [PMID]

[12] Mehlum L, Tørmoen AJ, Ramberg M, Haga E, Diep LM, Laberg S, et al. Dialectical behavior therapy for adolescents with repeated suicidal and self-harming behavior: A randomized trial. Journal of the American Academy of Child \& Adolescent Psychiatry. 2014; 53(10):1082-91. [DOI:10.1016/j. jaac.2014.07.003] [PMID]

[13] Werner S, Shulman C. Subjective well-being among family caregivers of individuals with developmental disabilities: The role of affiliate stigma and psychosocial moderating variables. Research in Developmental Disabilities. 2013; 34(11):4103-14. [DOI:10.1016/j.ridd.2013.08.029] [PMID]

[14] Ong L, Chandran V, Peng R. Stress experienced by mothers of Malaysian children with mental retardation. Journal of Paediatrics and Child Health. 1999; 35(4):358-62. [DOI:10.1046/ j.1440-1754.1999.00383.x]

[15] Delavar A. [Theoretical and practical foundations of research in humanities and social sciences (Persian)]. Tehran: Roshd Publications; 2001.

[16] Keyes CLM, Magyar-Moe JL. The measurement and utility of adult subjective well-being. In: Lopez, Shane J, Snyder, CR editors. Positive Psychological Assessment: A handbook of models and measures. Washington DC: American Psychological Association; 2003. [DOI:10.1037/10612-026]

[17] Golestani-Bakht T. [The model of subjective well-being and happiness in Tehran population (Persian)] [PhD dissertation] Tehran: Al-Zahra University; 2007.

[18] Lyubomirsky S, Lepper HS. A measure of subjective happiness: Preliminary reliability and construct vali- dation. Social Indicators Research. 1999; 46(2):137-55 [DOI:10.1023/A:1006824100041]

[19] Barkham M, Hardy GE, Startup M. The IIP-32: A short version of the inventory of interpersonal problems. British Journal of Clinical Psychology. 1996; 35(1):21-35. [DOI:10.1111/j.2044-8260.1996.tb01159.x] [PMID]

[20] Horowitz LM, Rosenberg SE, Baer BA, Ureño G, Villaseñor VS. Inventory of interpersonal problems: Psychometric properties and clinical applications. Journal of Consulting and Clinical Psychology. 1988; 56(6):885-92. [DOI:10.1037/0022006X.56.6.885] [PMID]

[21] Fath N, Azadfallah P, Rasoolzadeh-Tabatabaee K, Rahimi C. [Validity and reliability of the Inventory of Interpersona Problems (IIP-32) ) (Persian)]. Journal of Clinical Psychology. 2013; 5(3):69-80.

[22] Wagner AW, Rizvi SL, Harned MS. Applications of dialectical behavior therapy to the treatment of complex trauma-related problems: When one case formulation does not fit all. Journal of Traumatic Stress. 2007; 20(4):391-400 [DOI:10.1002/jts.20268] [PMID]

[23] Heiman T, Berger O. Parents of children with Asperger syndrome or with learning disabilities: Family environment and social support. Research in Developmental Disabilities. 2008; 29(4):289-300. [DOI:10.1016/j.ridd.2007.05.005] [PMID]

[24] Lengua LJ, Honorado E, Bush NR. Contextual risk and parenting as predictors of effortful control and social competence in preschool children. Journal of Applied Developmental Psychology. 2007; 28(1):40-55. [DOI:10.1016/j.appdev.2006.10.001] [PMID] [PMCID]

[25] Gutteling BM, Montagne B, Nijs M, van den Bosch LW. Dialectical behavior therapy: Is outpatient group psychotherapy an effective alternative to individual psychotherapy?: Preliminary conclusions. Comprehensive Psychiatry. 2012 53(8):1161-8. [DOI:10.1016/j.comppsych.2012.03.017] [PMID] 